\title{
NONDESTRUCTIVE EVALUATION OF DEFECTS AND OPERATING DAMAGE IN CFCC COMBUSTOR LINERS
}

\author{
J. G. Sun, S. Erdman, R. Russel, C. Deemer, W. A. Ellingson \\ Argonne National Laboratory \\ Argonne, IL 60439
N. Miriyala, J. B. Kimmel, and J. R. Price
Solar Turbines Inc.
San Diego, CA 92186

\begin{abstract}
Continuous fiber-reinforced ceramic composite (CFCC) liners with environmental barrier coatings (EBCs) have been successfully field tested for nearly 14,000 hours in a Solar Turbines engine. The outer liner was chemical-vapor-infiltrated (CVI) SiC/SiC CFCC, and the inner liner was melt-infiltrated (MI) SiC/SiC CFCC. To determine their condition and assess operating damage, the liners were nondestructively evaluated (NDE) during various processing stages, as well as before and after the field test. The NDE techniques included pulsed infrared thermal imaging, air-coupled ultrasonic scanning, and X-ray computed tomography (CT). The NDE results and their correlations with destructive examination data are presented in this paper.
\end{abstract}

\section{INTRODUCTION}

In the Ceramic Stationary Gas Turbine (CSGT) Program sponsored by the U.S. Department of Energy (DOE), the main objective is to utilize ceramic technology by selectively replacing cooled metallic hot-section components with ceramic parts (blades, nozzles, and combustor liners). A team led by Solar Turbines Inc. has successfully demonstrated in field tests the use of $\mathrm{SiC} / \mathrm{SiC}$ CFCC liners in turbines designed for reducing $\mathrm{NO}_{\mathrm{x}}$ and $\mathrm{CO}$ emissions. Because of the high recession rate of CFCC liners in the high steam environment of the gas turbine combustor, EBCs were applied on the hot surfaces of the CFCC liners to meet the 30,000-h life goal (Miriyala et al., 2001).

A set of CFCC inner and outer liners with EBCs was recently field tested at a Texaco facility (Bakersfield, CA, USA). The test was terminated after 13,937 hours of engine operation with 59 starts/stops, when a small hole was observed in the inner liner during routine borescope inspection. Honeywell Advanced Composites Inc. (HACI) fabricated the inner and outer liners used in the test. The inner liner was a Hi-Nicalon/SiC-Si composite made by the melt-infiltration (MI) process. The outer liner was an enhanced Hi-Nicalon/SiC composite made by the chemical-vapor-infiltration (CVI) process. A seal coat of $\mathrm{SiC}$ was applied on both liners using chemical vapor deposition for additional environmental protection. Both liners were 20 -cm long and about 3.7- $\mathrm{mm}$ thick. The diameter of the inner liner was $33 \mathrm{~cm}$, and that of the outer liner, $76 \mathrm{~cm}$. EBC coatings were subsequently applied to the gas-path surfaces of the two liners by United Technology Research Center (UTRC) using a thermal spray process. The total thickness of the coatings was about $450 \mu \mathrm{m}$. Fabrication details and analysis results for the coatings can be found in Kimmel et al. (2001). Figure 1 shows the liners after the EBC application. 




Fig. 1. Digital photo of CFCC liners after EBC application.

To determine their condition and assess operating damage, the liners were subjected to NDE at Argonne National Laboratory (ANL) during various processing stages, as well as before and after the engine test. The NDE techniques included pulsed infrared thermal imaging, aircoupled ultrasonic scanning, and X-ray CT (Sun et al., 1998, 1999; Sun, 2001). This paper presents the NDE results for the CFCC liners before and after the EBC application and after the engine test. The NDE data were also correlated with destructive microscopic examinations of the CFCC and EBC from the posttest evaluation.

\section{RESULTS}

\section{NDE Results of CFCC Liners}

Through-thickness infrared thermal imaging and air-coupled ultrasonic scanning were conducted to assess the conditions of the CFCC liners before the EBC application. The NDE data were presented as thermal diffusivity and ultrasonic transmission (UT) images mapping the entire liners (100\% inspection). The data indicated that thermal diffusivity was affected slightly by local thickness variations, as an average thickness was used for each liner to derive the local thermal diffusivity (Sun et al., 1999). The outer liner was found to be generally uniform and free of defects from both thermal diffusivity and air UT tests. However, a major defect area, about 42 $\mathrm{x} 18 \mathrm{~mm}$, was found at the lower edge of the inner liner.

Figure 2 shows the thermal diffusivity image of the inner liner. The defect region has low diffusivity at $\sim 35 \%$ of the normal region. To determine the defect type, X-ray CT and onesided thermal imaging were performed at this region. Figure 3 a shows a $0.5-\mathrm{mm}$-thick CT slice covering the depth range of $0.5-1 \mathrm{~mm}$ from the outside diameter (OD) surface, and Fig. $3 \mathrm{~b}$ is a one-sided thermal image taken at $0.1 \mathrm{~s}$ after the thermal flash. The defect region shows lower density in the CT image and higher surface temperature (brighter gray scale) in the thermal image. These results indicate that the defect is a delamination type. The one-sided thermal 
imaging data were further processed to determine the delamination depth. Figure $3 \mathrm{c}$ maps the predicted depth of the defect region. The delamination depth was about $0.9 \mathrm{~mm}$ from the OD surface, in agreement with the CT data.



Fig. 2. Thermal diffusivity image of Hi-Nicalon/SiC-Si MI inner liner.



(a)



(b)



(c)

Fig. 3. (a) X-ray CT image, (b) one-sided thermal image, and (c) predicted depth map for the defect indicated in Fig. 2.

\section{NDE Results of CFCC Liners after EBC Application}

Thermal imaging and air UT tests were conducted on the CFCC liners after the EBC application. While there was no apparent change in the NDE data for the outer liner, the data for the inner liner showed expanded areas of low diffusivity and low ultrasound transmission, as shown in Fig. 4. These results indicate delamination/dedonding of the EBC layers, where the EBC appeared to be intact according to visual observation. The EBC layers in the defect regions spalled off during the first borescope inspection, after approximately $900 \mathrm{~h}$ of engine operation. However, the test was continued until a hole in the inner liner was observed in an EBC spalled area, shown in Fig. 5, after 13,937 h of the engine test.



(a) 


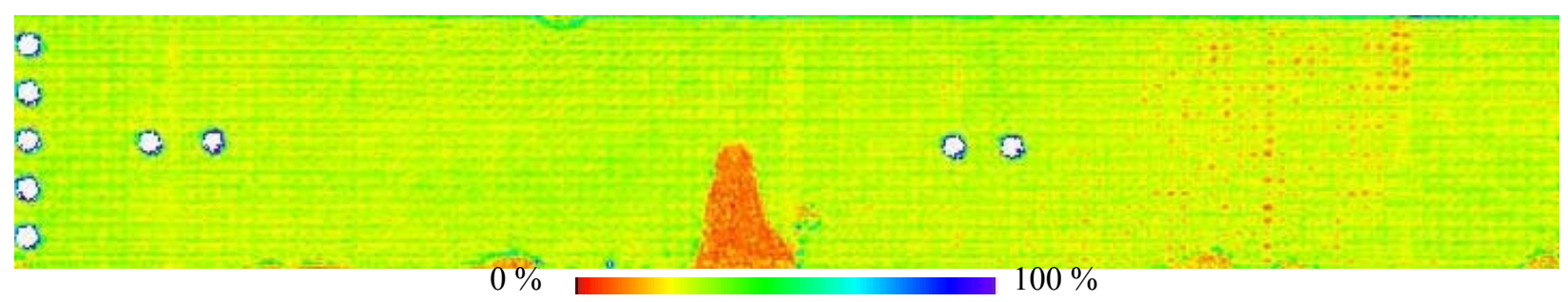

(b)

Fig. 4. (a) Thermal diffusivity image and (b) air-coupled UT image of Hi-Nicalon/SiC-Si MI inner liner after the EBC application.

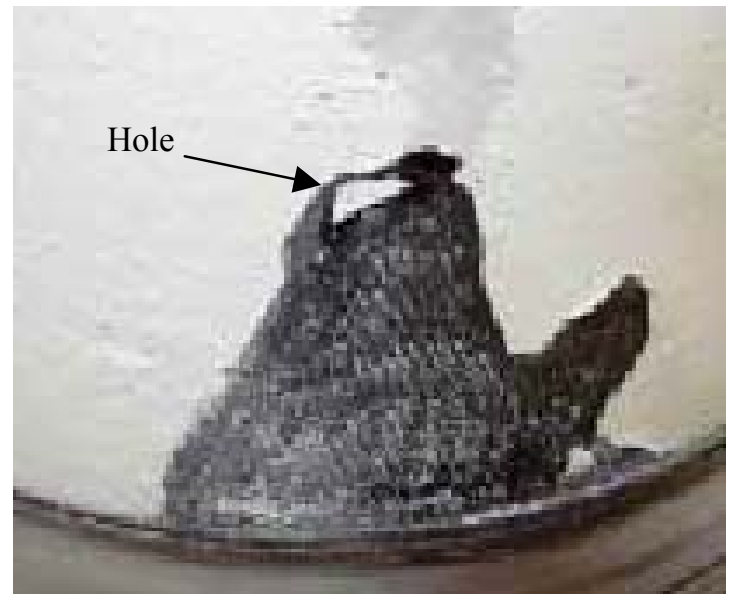

Fig. 5. Hole in an EBC spalled area of the inner liner that formed after 13,937 hours.

\section{NDE Results of Field-Engine-Tested Liners}

Digital images of the EBC-coated (hot side) surfaces of the outer and inner liners are shown in Fig. 6. It is evident that the $\mathrm{EBC}$ was still present on large sections of the liners. However, EBC loss occurred at the aft-end edge (lower edge) and in the middle on both liners. The EBC loss in the middle of the liners occurred in areas where fuel injectors were located, i.e., the hottest areas. The location, size, and geometry of the defect regions after EBC application (Fig. 4) correlated with the EBC spalled areas (Fig. 6b) for the inner liner.

Thermal imaging and air UT tests were again conducted on the engine-tested liners. Figure 7 shows the thermal diffusivity image of the outer liner. The regions around the EBC spalled areas were found to have lower diffusivities. Close examination of these regions indicated that the EBC had debonded from the CFCC liner and could be easily scratched off.

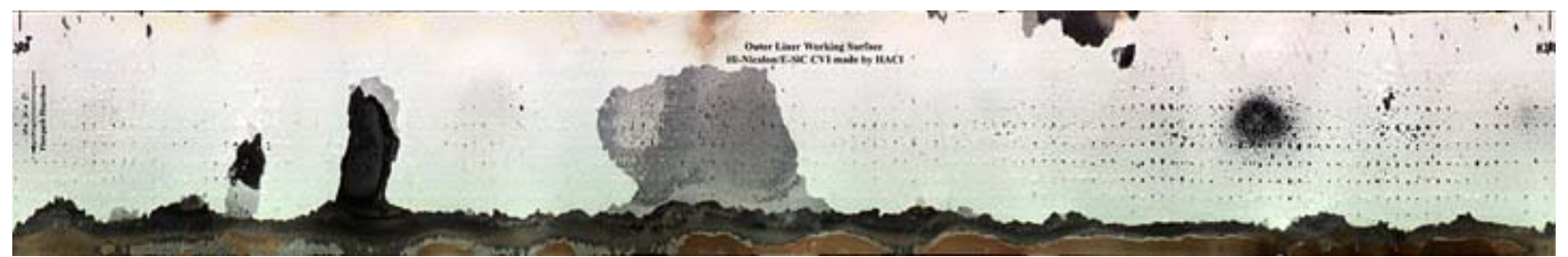

(a) 


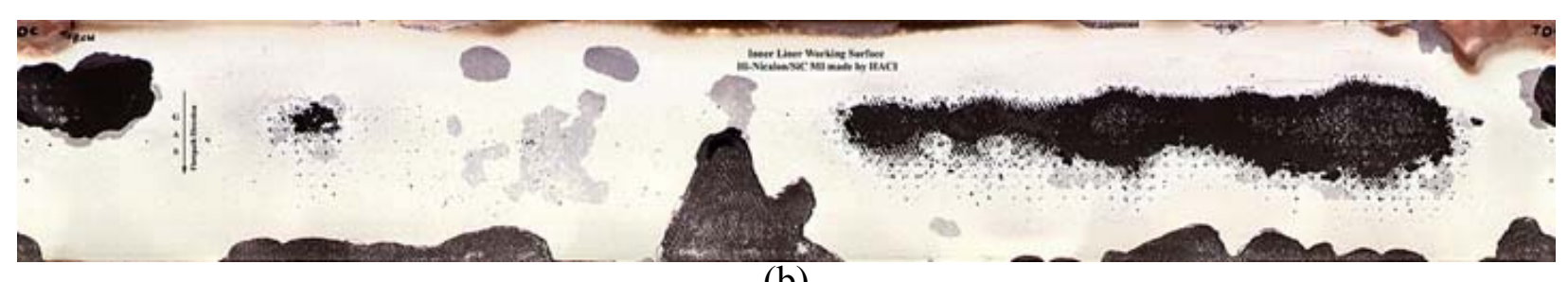

(b)

Fig. 6. Digital images of the EBC-coated surfaces of (a) outer liner and (b) inner liner after the 13,937-h field test.

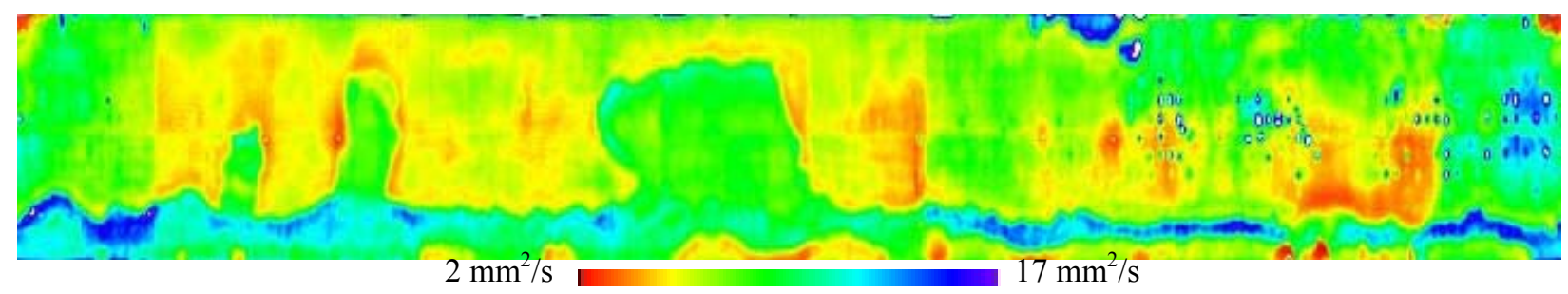

Fig. 7. Thermal diffusivity image of Hi-Nicalon/SiC CVI outer liner after the 13,937-h field test.

\section{Correlation of NDE Data with Microstructural Evaluation}

Both liners were sectioned for microstructural analyses after the 13,937-h engine test. Additional NDE data were taken on a few sections for detailed correlation with the microstructures of the CFCC and the EBC. Figure 8 shows the correlation of one-sided thermal imaging data with cross-sectional photomicroscopy of the outer liner. The thermal image was taken before the sample was cut. It contains three gray-scale levels: the black (low surface temperature) regions represent the bare CFCC surfaces where EBC has spalled; the intermediate gray-scale regions indicate where the $\mathrm{EBC}$ has relatively good bonding with the subsurface CFCC; the bright (higher surface temperature) regions, extensively shown in the image with large and small areas, are the locations where EBC has debonded from the subsurface CFCC. Most of the EBC-debond areas surround regions/spots where EBC has spalled. Cross-sectional photomicrographs shown in Fig. 8 clearly indicate the EBC debond under a large surface area at the top and many pinhole areas at the bottom. The formation of the EBC pinholes was attributed to the surface asperities in the as-processed CFCC liners, which causes vertical cracking in the EBC (Kimmel et al., 2001). 


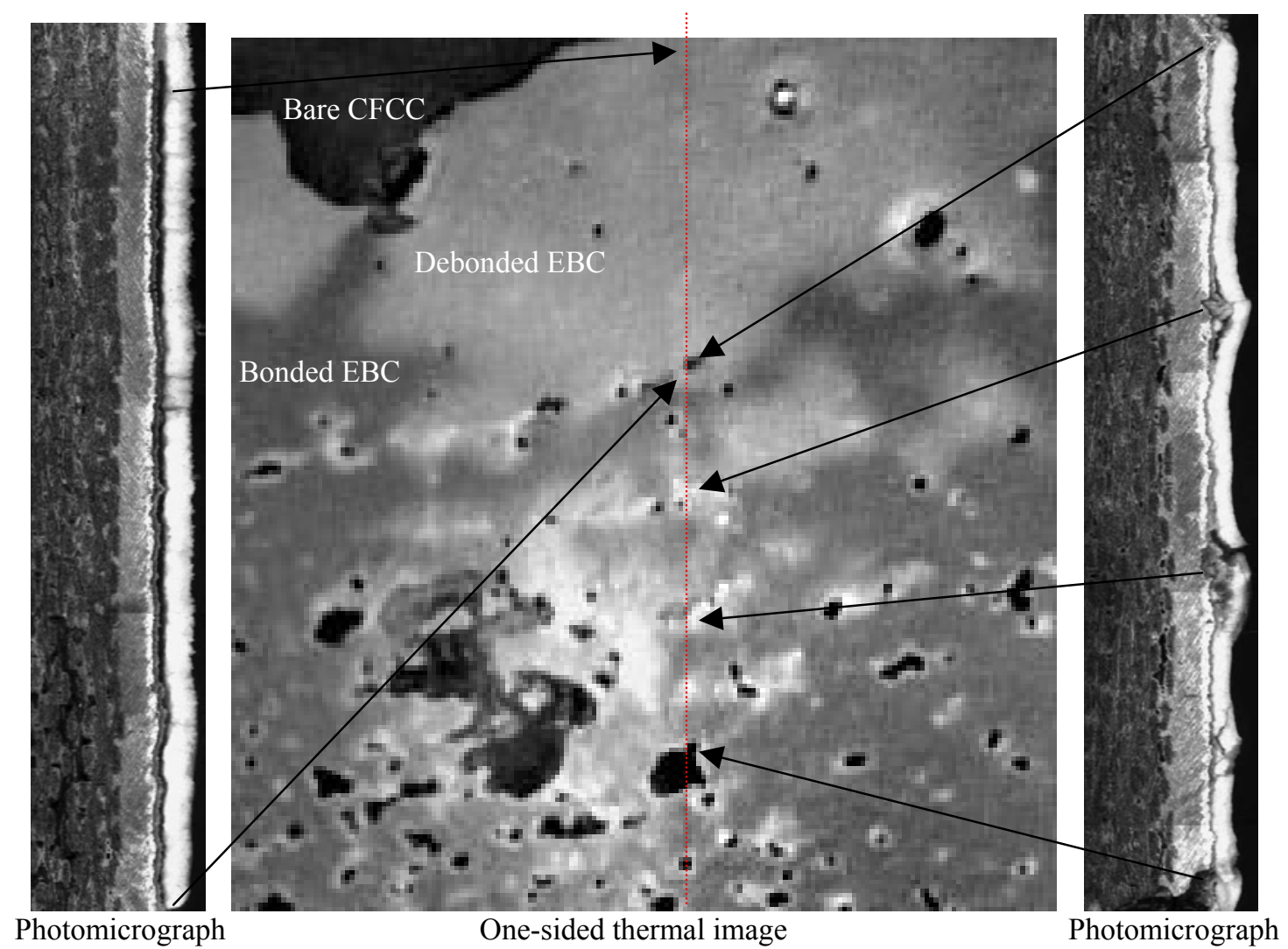

Fig. 8. Correlation of cross-sectional photomicrographs with one-sided thermal image showing locations where EBC debonding and pre-spall occur.

\section{CONCLUSIONS}

Infrared thermal imaging, air-coupled UT scanning, and X-ray CT NDE techniques have been successfully used to characterize full-scale CFCC combustor liners with EBC coatings that were tested for 13,937 hours in a Solar Turbines engine. A pre-existing delamination defect in the CFCC inner liner was detected by all NDE techniques. NDE data taken before the engine test were able to predict where EBC spallation would occur in terms of location, size, and geometry. Also, NDE data taken after the field test correlated with destructive photomicroscopy and showed that EBC regions which might spall with further testing could be detected by NDE techniques.

\section{ACKNOWLEDGMENTS}

This work was partially funded by the U.S. Department of Energy, Energy Efficiency and Renewable Energy, Office of Industrial Technologies, under Contract W-31-109-ENG-38, and partially funded under DOE Contracts DE-AC02-92CE40960 and DE-FC02-00CH11049.

\section{REFERENCES}


Kimmel, J., Miriyala, N., Price, J., More, K., Tortorelli, P., Eaton, H., Linsey, G., and Sun, E., 2001, "The Evaluation of CFCC Liners with Environmental Barrier Coatings after Field Testing in a Gas Turbine," presented at the UEF Conference on Structural Ceramic and Ceramic Composites for High Temperature Applications, Seville, Spain, October 11, 2001.

Miriyala, N., Fahme, A., and van Roode, M., 2001, "Ceramic Stationary Gas Turbine Program Combustor Liner Development Summary," ASME Paper 2001-GT-512, presented at the International Gas Turbine and Aeroengine Congress and Exposition, New Orleans, Louisiana, USA, June 2001.

Sun, J. G., Easler, T. E., Szweda, A., Pillai, T. A. K., Deemer, C., and Ellingson, W. A., 1998, "Thermal Imaging and Air-Coupled Ultrasound Characterization of a Continuous Fiber Ceramic Composite," in Ceramic Engineering and Science Proceedings, Ed. D. Bray, Vol. 19, Issue 3, pp. 533-540.

Sun, J. G., Deemer, C., Ellingson, W. A., Easler, T. E., Szweda, A., and Craig, P. A., 1999, "Thermal Imaging Measurement and Correlation of Thermal Diffusivity in Continuous Fiber Ceramic Composites," in Thermal Conductivity 24, Eds. P. S. Gaal and D. E. Apostolescu, pp. 616-622.

Sun, J. G., 2001, "Method for Determining Defect Depth Using Thermal Imaging," U.S. patent pending. 